\title{
Profile of certolizumab and its potential in the treatment of psoriatic arthritis
}

This article was published in the following Dove Press journal:

Drug Design, Development and Therapy

13 April 2013

Number of times this article has been viewed

\author{
Maria Sole Chimenti' \\ Rosita Saraceno ${ }^{2}$ \\ Andrea Chiricozzi ${ }^{2,3}$ \\ Alessandro Giunta ${ }^{2}$ \\ Sergio Chimenti ${ }^{2}$ \\ Roberto Perricone' \\ 'Unit of Rheumatology, Allergology, \\ and Clinical Immunology, ${ }^{2}$ Unit \\ of Dermatology, University of Rome \\ Tor Vergata, Rome, Italy; ${ }^{3}$ Laboratory \\ for Investigative Dermatology, \\ Rockefeller University, New York, \\ NY, USA
}

\begin{abstract}
Psoriatic arthritis (PsA) is a chronic inflammatory arthropathy associated with psoriasis (PsO). PsA could be considered an enthesal disease because of the link between mechanical stress (entheses) and immunologically active tissue (synovium). Evidence of efficacy of anti-tumor necrosis factor alpha (TNF- $\alpha$ ) is supported by reduction of histological vascularity and immune cell infiltrates in synovial tissue after treatment. Certolizumab pegol (CZP) is a polyethylene glycolylated (PEGylated) Fab' fragment of a humanized monoclonal antibody that binds and neutralizes human TNF- $\alpha$. The PEG moiety of the Fab fragment, markedly increases the half-life of CZP and confers to the drug a unique structure that differs from the other antiTNF- $\alpha$ agents tested for the treatment of Crohn's disease, rheumatoid arthritis, ankylosing spondylitis, axial spondyloarthritis, nonradiographic spondyloarthritis, PsO, and PsA. In contrast to other anti-TNF- $\alpha$ agents, CZP did not mediate increased levels of apoptosis, suggesting that these mechanisms are not essential for the anti-TNF- $\alpha$ efficacy in Crohn's disease. As CZP, infliximab, and adalimumab, but not etanercept, almost completely inhibited lipopolysaccharideinduced interleukin-1 beta release from monocytes, this cytokine-production inhibition may be relevant for drug efficacy. Due to these characteristics, it has been demonstrated in clinical studies that CZP effectively improves signs and symptoms of arthritis and physical function and skin manifestations of $\mathrm{PsO}$, with a safety profile similar to rheumatoid arthritis. This drug can be considered as a valid treatment in patients affected by PsA. The efficacy and tolerability profiles suggest CZP as a suitable antipsoriatic drug in the treatment of PsA.
\end{abstract}

Keywords: psoriatic arthritis, certolizumab pegol, biological therapies, anti-TNF

\section{Introduction}

Psoriatic arthritis (PsA) is a chronic inflammatory arthropathy commonly associated with psoriasis (PsO). Several epidemiologic studies have examined the association between PsO and inflammatory arthritis. In studies performed in outpatients suffering from $\mathrm{PsO}$, arthritis prevalence varied from 6\% to $39 \% .{ }^{1}$ Joint disease is characterized by systemic inflammation and extensive synovitis, resulting in erosions of articular cartilage leading to joint destruction. Progressive damage begins early in the course of the disease as a consequence of the active inflammation, and results in radiological damage in up to $47 \%$ of patients at a median interval of 2 years, causing irreversible disability. ${ }^{2}$ PsA belongs to the spondyloarthritis ( $\mathrm{SpA}$ ) group and affects primarily the peripheral joints, the spine, and the entheses. The pathogenesis of PsA is linked to innate immune response that generates high concentrations of inflammatory cytokines, such as tumor necrosis factor alpha $(\mathrm{TNF}-\alpha)$, which promotes effector function of a variety of tissue cells and thereby sustains the chronic inflammation leading to synovitis in
Correspondence: Maria Sole Chiment Unit of Rheumatology, Department of Internal Medicine, University of Rome Tor Vergata, I Via Montpellier,

Rome 00163, Italy

Tel +390620900587

Fax +3906 20900358

Email maria.sole.chimenti@uniroma2.it 
PsA. ${ }^{3}$ Overexpression of TNF- $\alpha$ is believed to play a key role in the pathogenic mechanisms linking $\mathrm{PsO}$ and arthritis. ${ }^{4}$ This cytokine has been implicated in a number of inflammatory diseases, including PsA, by inducing the production of other inflammatory cytokines such as interleukin (IL)-1 and IL-6, chemokines like IL-8, and degradative enzymes, including several matrix metalloproteinases. ${ }^{5}$ Moreover, it mediates a number of biological processes that can result in joint damage characterized by stimulation of bone resorption and inhibition of bone formation and of synthesis of proteoglycans. TNF- $\alpha$ may also contribute to vascular proliferation, which is probably one of the key and earlier observable changes in psoriasis and PsA. ${ }^{6}$ Therapies neutralizing pivotal cytokines might not only limit joint damage and skin inflammation but also reduce the incidence of adverse metabolic and cardiovascular events in affected patients. ${ }^{7}$ Several trials have shown excellent clinical results with anti-TNF- $\alpha$ agents, etanercept,${ }^{8}$ infliximab, ${ }^{9}$ adalimumab, ${ }^{10}$ and golimumab. ${ }^{11}$ These agents have been proven to be effective in different aspects of the disease, including skin lesions, joint pain and swelling, enthesitis, and dactylitis, resulting in a significant improvement both in mobility and in radiographic progression and quality of life $(\mathrm{QoL})$ parameters. ${ }^{12}$ Recently, certolizumab pegol (CZP) has been tested and evaluated for several inflammatory diseases, and for its safety and efficacy profiles. This drug can also be considered for the treatment of PsA. In this review, we investigated the pathogenetic roles of $\mathrm{TNF} \alpha$ in inflammatory arthritis as PsA, and the mechanisms of action of CZP. In particular, the evidence of efficacy of CZP in PsA will be explored.

\section{Pathogenesis of PsA: link with TNF- $\alpha$}

Although the biological function of TNF- $\alpha$ is not completely clear in both normal and pathological conditions, elevated levels of TNF- $\alpha$ have been found in patients experiencing inflammatory diseases, and clinical data on the efficacy of TNF- $\alpha$-blocking agents suggest that it plays a key role in the pathogenesis of various inflammatory disorders such as Crohn's disease (CD), rheumatoid arthritis (RA), and SpA, as well as $\mathrm{PsO}$ and $\mathrm{PsA} .{ }^{13}$ PsA pathogenesis is incompletely understood, and a pathophysiological role of the synovium has been recently suggested. Some authors consider PsA as an enthesal disease linking mechanical stress (entheses) to immunologically active tissue (synovium). ${ }^{4} \mathrm{~A}$ dermatological perspective brings an alternative view of autoimmunity that could partly explain the role of innate immunity. The skin may likely secrete proinflammatory mediators, such as TNF- $\alpha$, to the affected proximal or distant joints, and the interruption of this pathological communication may represent a therapeutic target ${ }^{14}$ (Figure 1). TNF- $\alpha$ produced by macrophage infiltration in synovial tissue may constitute the basis of synovium hypersensitization to endogenous ligands of the innate immune system. ${ }^{15}$ Synovial tissue analysis has been used in order to distinguish PsA from other inflammatory arthritis, particularly in terms of pathological aspects and response to synthetic or biological diseasemodifying antirheumatic drugs (DMARDs). ${ }^{16}$ Recent findings suggest an important feature of PsA synovium: the presence of lymphoid aggregates of variable size and organization, previously considered highly specific of RA while recently observed in other inflammatory arthritis as PsA. Two major cytokines are involved in the pathogenesis of lymphoid aggregates: TNF- $\alpha$ and lymphotoxin beta. They play a potential role in the development of the high endothelial venule phenotype and in the expression of homing chemokines. Moreover, increased levels of these cytokines have been demonstrated in PsA synovial fluid. ${ }^{17}$ It has been suggested that these structures linked to inflammatory cytokines may play a role in multiple processes, including antigen presentation, T-cell costimulation, and synthesis of soluble mediators. ${ }^{18}$ For this reason, TNF- $\alpha$-targeting agents represent a valuable therapeutic approach in treating such disorders as PsA. There are five marketed agents targeting TNF- $\alpha$ that possibly have a complex mechanism of action beyond the plain TNF- $\alpha$ neutralization. They differ in structure, pharmacokinetic, and in vitro properties, all of which may have relevant therapeutic implications.

\section{Treatment of PsA: evidence of anti-TNF- $\alpha$ efficacy}

Few studies have focused on the correlation between clinical composite scores and changes in PsA synovium. Treatment with DMARDs can modify synovial cell populations and infiltrates, correlating with the clinical improvement observed in treated patients. ${ }^{19}$ One of the first studies establishing the efficacy of anti-TNF- $\alpha$ in modifying synovial tissue in PsA showed reduced vascularity and suppression of immune cells after treatment with infliximab. ${ }^{20}$ In particular, the authors of this study evaluated the effects of anti-TNF- $\alpha$ treatment on histologic abnormalities of the synovium in patients with SpA in order to confirm a potential benefit on peripheral synovitis and to investigate the mechanism of action of anti-TNF- $\alpha$ agents. Histologic and immunohistochemical data showed a significant decrease in vascular cell adhesion molecule 1 

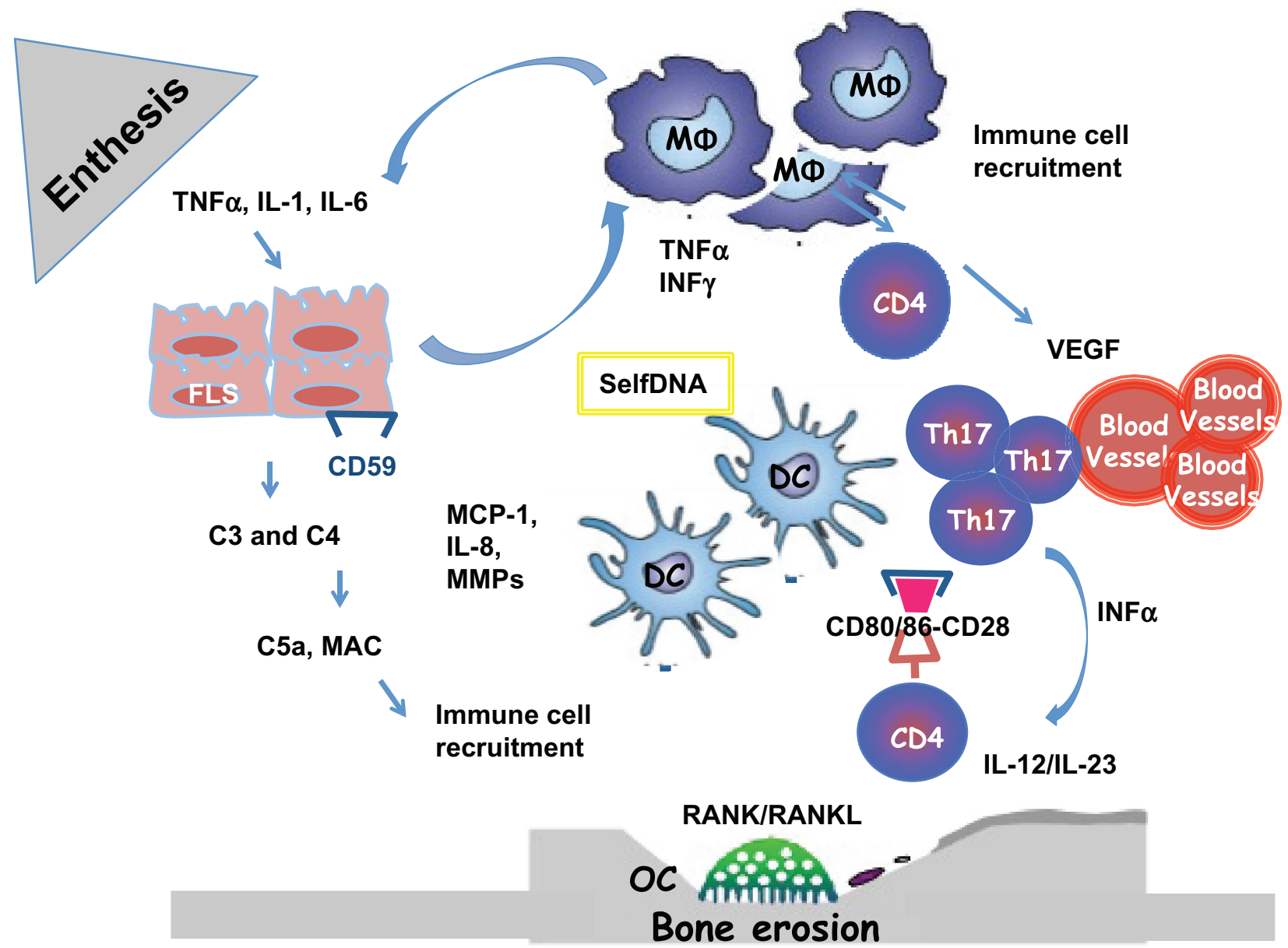

Figure I Enthesal and Joint pathology in Psoriatic Arthritis. The origin of Inflammation in the enthesal complex in PsA is multifactorial. When stimulated by stress, infections and trauma (Koebner phenomenon), in a genetic background, fibroblast-like synoviocytes express selfDNA or/ and secrete inflammatory cytokines and MMPs. They produce complement system factors as C3 and C4 and express less CD59 during inflammation, who is an inhibitor of complement system activation. The activation of the complement system lead to the release of C5a and production of MAC with the lysis of cells and recruitment of immune cells. FLS secrete MCP-I and IL-8 necessary for recruitment and activation of MФ. Polyclonal activation of CD4+Tcells and ThI7 is the consequence of the immunological synapse with DC linked to the binding with CD80/86 and CD28. When activate CD4+ Tcells produce: RANKL with activation of OC with the consequence of bone erosions and VEGF with the activation of endothelial cells and the formation of HEV

Abbreviations: PsA (Psoriatic Arthritis); FLS (fibroblast-like synoviocytes); TNF (Tumor Necrosis Factor); MMP (Matrix metalloproteinases); MCP-I (monocyte chemotactic protein-I); OC (Osteoclast); MФ, (monocytes/macrophages); RANK/RANKL (Receptor activator of nuclear factor kappa-B/ ligand); MAC (membrane attack complex); VEGF (vascular endothelial growth factor); ThI7 (T helper 17); DC (dendritic cell); CD (cluster differentiation).

expression on the synovial endothelium, a reduction in neutrophil and macrophage infiltration of the synovial sublining layer, and diminished presence of macrophagelike synoviocytes. The aforementioned properties suggest that primarily anti-TNF- $\alpha$ agents act in deactivating the endothelium, with a decrease in vascularity, which in turn reduces migration and homing of inflammatory cells into the synovial tissue. Additionally, the thickness of the synovial lining was normalized after only 12 weeks of treatment. This effect is possibly mediated by a reduction in TNF- $\alpha$-induced proliferation and/or restoration of Fasmediated apoptotic cell death of synovial fibroblasts. ${ }^{20}$ Moreover, the number of CD55-positive synovial lining fibroblasts was significantly reduced at week 12 . The most striking immunohistopathological changes included a reduction in lining layer thickness and in downregulation of hypervascularity and in endothelial activation, resulting in a decrease of the inflammatory cell infiltrate with differential effects on T and B cells. ${ }^{21}$ Kruithof et al demonstrated a significant reduction in CD3-positive cells in a cohort of PsA patients treated with adalimumab. Interestingly, a significant reduction in the number of CD3-positive cells was observed after only 4 weeks of treatment. ${ }^{22}$ Systemic modifications of the inflammatory process during antiTNF- $\alpha$ treatment concern mediators of inflammation. In fact, the evaluation of complement-system fragments in patients with PsA treated with anti-TNF- $\alpha$ agents showed a significant decrease in plasma $\mathrm{C} 3$ and $\mathrm{C} 4$ levels, independently from the anti-TNF- $\alpha$ used. Patients with good response showed a more pronounced reduction in serum 
complement C3 levels as well as low baseline C3 levels. These findings underline that a reduction in complement native components may be considered as an improvement of a preexisting proinflammatory status reverted by antiTNF- $\alpha$ drugs. It could be postulated that persistently elevated $\mathrm{C} 3$ levels may represent a negative predictive factor influencing the outcome of anti-TNF- $\alpha$ therapy in RA and PsA. As a consequence, the detection of blood C3 levels may provide an additional tool in monitoring disease activity during treatment with anti-TNF- $\alpha$ in PsA patients. ${ }^{23}$ Recently, the Group for Research and Assessment of Psoriasis and Psoriatic Arthritis (GRAPPA) reported recommendations for PsA treatment. ${ }^{12}$ An excellent therapeutic improvement has been obtained by the introduction of biologic treatments designed to modify and regulate pivotal and specific mechanisms involved in PsO and PsA immunopathogenesis. To date, anti-TNF- $\alpha$ has been suggested to have a more favorable side-effect profile than synthetic DMARDs. ${ }^{24}$

\section{Profile of certolizumab}

\section{Structural function}

CZP (Cimzia; UCB, Brussels, Belgium) is a PEGylated (polyethylene glycol) Fragment antigen binding (Fab) of a humanized monoclonal antibody that binds and neutralizes human TNF- $\alpha$. The structure of CZP differs significantly from the other agents that have undergone clinical evaluation. In vivo, the pharmacokinetic properties of Fab are limited. However, attachment of a $40 \mathrm{kDa}$ PEG moiety to the Fab fragment markedly increases the half-life of CZP to a value comparable with that of a whole-antibody product, conferring to the drug a fast and lasting effect on the inhibition of joint damage and inflammation. The Fab fragment was engineered with a single free-cysteine residue in the hinge region, which enables site-specific attachment of PEG without affecting the ability of the Fab fragment to bind and neutralize TNF- $\alpha .^{26,27}$ The unique structure of CZP differs from that of other anti-TNF- $\alpha$ agents that have been tested for the treatment of CD, RA, ankylosing spondylitis (AS), axial SpA, nonradiographic SpA, PsO, and PsA. In fact, clinical efficacy of the drug reported in clinical trials highlighted the rapid improvement of CZP in signs and symptoms of inflammatory arthritis.

\section{Mechanisms of action of CZP}

Concerning the mechanism of action of this drug, it is not clear why CZP does not induce apoptosis of cells bearing TNF$\alpha$, conversely to other anti-TNF- $\alpha$ agents. Hypothetically, in contrast to the other TNF- $\alpha$-targeting drugs, CZP may bind to a different epitope compared to the other agents, which leads to a different intracellular signaling pattern. Increased apoptosis has been reported in tissue sections from affected bowel after 24 hours and 6 and 28 days of infliximab treatment. ${ }^{28}$ It is possible that the anti-inflammatory effect of infliximab indirectly induces apoptosis of activated cells. In this context, a series of comparative in vitro studies were conducted in order to explore the mechanism of action of CZP in CD. The mechanisms, including induction of apoptosis, antibody-dependent cell-mediated cytotoxicity (ADCC), and complement-dependent cytotoxicity (CDC), may not be required for clinical efficacy of an anti-TNF- $\alpha$ agent in $\mathrm{CD}$, however, inhibition of bacterially stimulated cytokine production from macrophages may be needed for the function of an anti-TNF- $\alpha$ agent to produce efficacy. In fact, in contrast to the other anti-TNF- $\alpha$ agents tested, CZP did not mediate increased levels of apoptosis in any of the in vitro assays used, suggesting that these mechanisms are not essential for the efficacy of anti-TNF- $\alpha$ agents in CD. As CZP, infliximab, and adalimumab, but not etanercept, almost completely inhibited lipopolysaccharide-induced IL-1- $\beta$ release from monocytes, this mechanism of inhibition of cytokine production may be important for efficacy of anti-TNF- $\alpha$ agents. ${ }^{29}$ Recently, Ueda et al investigated the cytotoxic effects of the anti-TNF- $\alpha$ agents CZP and golimumab. ${ }^{30}$ Upon evaluation of their ability in binding to transmembrane TNF- $\alpha$ (tmTNF- $\alpha$ ), and in inducing ADCC and CDC, both agents were proven effective in neutralizing tmTNF- $\alpha$. In contrast to CZP, golimumab was also able to induce ADCC and $\mathrm{CDC}$, similarly to infliximab and adalimumab. While CZP directly provoked nonapoptotic cell death in tmTNF$\alpha$-expressing cells, golimumab generated a weaker apoptotic effect compared to infliximab and adalimumab. Accounting for these properties, the cytotoxic effects of anti-TNF- $\alpha$ agents on TNF- $\alpha$-expressing cells underline their efficacy in treating granulomatous diseases. ${ }^{30}$ The direct cytotoxic effect of CZP on TNF- $\alpha$-producing cells may contribute to the clinical effectiveness in the treatment of $C D$, whereas golimumab may be less effective for the treatment of granulomatous diseases..$^{28,30}$

\section{Intracellular signal transduction of CZP}

Another important concern about the mechanism of action of CZP is the evidence of the intracellular signal transduction triggered by the drug. All available anti-TNF- $\alpha$ biologics have in common the capability to effectively neutralize TNF- $\alpha$ as a major pharmacological mechanism of action. 
However, there are distinctions with respect to the effect of engagement with tmTNF- $\alpha$. In all cases, anti-TNF- $\alpha$ biologics can act as antagonists by blocking interaction between tmTNF- $\alpha$ and TNFR1/2 (Tumor necrosis factor receptor 1/2) expressed on a responsive cell. A recent study reported similar ability of CZP, adalimumab, and infliximab in neutralizing mTNF-a-mediated (membrane Tumor necrosis factor- $\alpha$ mediated) signaling, whereas etanercept appeared to be about twofold less potent. ${ }^{31}$ However, in certain instances, an antiTNF- $\alpha$ may also act as an agonist through the phenomenon known as "reverse signaling," in which the engagement of tmTNF- $\alpha$ leads to phosphorylation of specific serine residues in the cytoplasmic tail of tmTNF- $\alpha$ and a signal is transduced in the cell expressing tmTNF- $\alpha .^{32,33}$ Furthermore, regulated intramembrane proteolysis of tmTNF- $\alpha$ by signal peptide peptidase-like proteases is reported to release a TNF- $\alpha$ intracellular domain mediating reverse signaling in dendritic cells. The full significance of reverse signaling is unknown. One consequence of reverse signaling through tmTNF- $\alpha$ in activated human T cells by both etanercept and infliximab is the induction of E-selectin. ${ }^{34,35}$ However, by binding only a single TNF- $\alpha$ homotrimer, etanercept does not cross-link tmTNF- $\alpha$ (in the absence of rheumatoid factor), contrary to bivalent mAbs (monoclonal antibodies) such as infliximab. In this regard, it is interesting to highlight that infliximab, but not etanercept, suppresses T-cell proliferation by inducing $\mathrm{G}_{0} / \mathrm{G}_{1}$ cell-cycle arrest. Although the rheumatoid factor positively interferes in cross-linking etanercept to tmTNF- $\alpha$, the suppression of cell proliferation is weakly observed, approximately half the level occurring with infliximab. ${ }^{36}$ Another possible consequence of reverse signaling induced by biologic anti-TNF- $\alpha$ relates to intracellular events and potential competition for shared signaling pathway molecules, in particular those induced by endotoxin-mediated TLR (Toll-like receptor) signaling, given the observation that in vitro reverse signaling through tmTNF- $\alpha$ induces endotoxin resistance and suppression of cytokines, including TNF- $\alpha$, IL-1 $\beta$, IL-10, and IL-12. ${ }^{37}$ Regarding cytokines, as mentioned above, various in vitro studies report that infliximab and/or adalimumab markedly suppress lipopolysaccharide-induced production of cytokines, including TNF- $\alpha$, IL-1 $\beta$, IL-10, and IL-12, as well as CZP whereas this does not occur with etanercept. ${ }^{28,38}$

\section{First data on the efficacy of CZP}

An interesting study performed by Nesbitt et al compared the biological effects of CZP to other anti-TNF- $\alpha$ agents. ${ }^{28}$ The different spectrum of biologic effects mediated by TNF- $\alpha$ has hampered efforts to define the mechanisms of action of these agents. Although CZP can bind to human polymorphonuclear cells no increase in cell death or release of myeloperoxidase was observed, possibly because of a difference in the way in which it signals through membrane mTNF. In contrast, the other three anti-TNF- $\alpha$ agents all induced both cell death and release of myeloperoxidase. In contrast with these biological differences between the drugs, no clinical studies were performed to compare the clinical efficacy between the five anti-TNF- $\alpha$ agents available. Actually, positive clinical outcomes from the PRECISE study on CZP in CD provided an opportunity to reassess available data from infliximab, adalimumab, and etanercept clinical trials. ${ }^{39,40}$ CZP, infliximab, and adalimumab appear to be similar in terms of induction, maintenance of response, and remission, as reported in the PRECiSE ${ }^{40}$, ACCENT I (A Crohn's Disease Clinical Trial Evaluating Infliximab in a New Long-term Treatment Regimen) and CHARM (Crohn's Trial of the Fully Human Antibody Adalimumab for Remission Maintenance) trials. ${ }^{41,42}$

\section{Use of certolizumab in inflammatory arthritis: is there a rationale in psoriatic disease? Distribution of CZP in inflamed tissues}

The main feature of CZP is the distribution of the drug in inflamed tissues due to the effect of PEGylation. This aspect has been investigated using a noninvasive biofluorescence labeling methodology in murine arthritis. ${ }^{43} \mathrm{CZP}$, adalimumab, and infliximab distributed more effectively into inflamed tissue rather than noninflamed tissue. The penetration of CZP into arthritic paws was greater compared with adalimumab and infliximab, as was the duration of drug exposure in the inflamed tissue. These important features, characterizing CZP activity, may be attributed to the PEGylation and the smaller molecular weight. Exposure to a drug at the site of inflammation may be relevant in terms of efficacy for the treatment of inflammatory disorders such as inflammatory arthritis, namely RA and PsA. In this context, Palframan et al developed an in vivo methodology, enabled to measure antibody-type reagents in normal and inflamed tissue by detecting the distribution of TNF- $\alpha$, using a novel noninvasive biofluorescence method. ${ }^{44}$ This technique indicated the ratio of penetration of CZP into inflamed arthritic paws compared with normal tissue was greater than that observed with adalimumab and infliximab. Furthermore, the duration of exposure in the inflamed versus normal tissue was more prolonged for $\mathrm{CZP}$ than for both adalimumab and 
infliximab, and the accumulation of CZP in diseased tissue was more responsive to the severity of inflammation when compared with adalimumab and infliximab. These distinct structural features may affect efficacy, tolerability, rapidity, and/or sustainability of effect of CZP. ${ }^{45}$ In support of these findings, CZP was tested in inflammatory noninfectious diseases.

\section{Clinical efficacy of CZP in active RA}

Clinical efficacy of CZP in inflammatory arthritis - RA, ${ }^{46}$ PsA, ${ }^{47}$ and $\mathrm{SpA}^{48}$ - was evaluated in several clinical trials (Table 1). However, the first clinical evidence comes from the use of CZP in the treatment of CD. ${ }^{39}$ Actually, in Europe, CZP in combination with methotrexate (MTX) is indicated for the treatment of moderate to severe active RA in adult patients when the response to DMARDs including MTX has been inadequate. CZP can be given as monotherapy in case of intolerance to MTX or when continued treatment with MTX is contraindicated. ${ }^{49}$ The drug has been shown to reduce the rate of progression of joint damage, as measured by X-ray, and to improve physical function when given in combination with MTX. ${ }^{50}$ Moreover, CZP was associated with a rapid, consistent clinical response in a diverse group of RA patients, including those with prior TNF$\alpha$-inhibitor exposure in the Dose Flex dose-comparison trial. ${ }^{51}$ Dose Flex was a 34-week, phase IIIb, open-label, run-in, double-blind, placebo (PBO)-controlled randomized study in patients with active RA on stable-dose MTX. Of 333 patients who entered the run-in, $53.5 \%$ had prior TNF$\alpha$-inhibitor use. CZP demonstrated similar efficacy in RA patients with or without prior exposure to TNF- $\alpha$ inhibitors over 34 weeks of treatment. When CZP was withdrawn at week 16 in American College of Rheumatology 20 (ACR20) responders, a greater maintenance of response in patients who had not previously been exposed to TNF- $\alpha$ inhibitors was observed. Moreover, a long-term safety study of $400 \mathrm{mg}$ CZP for the treatment of RA was made with a period of observation of over 5 years. ${ }^{51}$ Patients in the FAST4 WARD trial ${ }^{52}$ were monitored for safety. The retention rates were reported up to week 280 (5.4 years) and safety results up to week 364. Adverse events (AEs) and serious AEs, as well as the number of serious infections, were similar between CZP and PBO; these findings were in the range of those reported for anti-TNF- $\alpha$. Therefore the use of CZP $400 \mathrm{mg}$ combination or monotherapy has been confirmed to have an acceptable long-term safety profile in line with what would be expected from an anti-TNF- $\alpha$ agent. ${ }^{52,53}$

\section{Clinical efficacy of CZP \\ and quality of life in SpA}

Following the excellent results observed in patients affected by RA, as well as in patients affected by CD treated with CZP, the drug was tested in randomized clinical trials ${ }^{48,54}$ in SpA patients. Axial SpA (axSpA) is a form of SpA that includes both AS and nonradiographic axial SpA (nr-axSpA), as defined by the Assessment of Spondyloarthritis International Society criteria. ${ }^{55}$ Both subgroups of patients have been shown to have a similar burden on QoL. In particular, the effect of CZP on signs and symptoms of AS and nr-axSpA was evaluated in a 24-week, double-blind, randomized, PBOcontrolled phase III trial; ${ }^{54} 325$ patients were randomized. Baseline characteristics were similar between groups. ${ }^{54}$ Improvements in the CZP-treated groups were observed in pain, fatigue, Bath Ankylosing Spondylitis Functional Index, and AS-QoL from the first measurement at week 1 through to week 24 compared to PBO. Patients in the CZPtreated arm had greater improvements in all the parameters studied compared to PBO. Improvements were also seen in the Medical Outcomes Study, the Short Form (36) Health Survey Mental Component Summary, and domains. CZP effectively improved patient-relevant outcomes in the broad population of axSpA patients classified using the Assessment of Spondyloarthritis International Society criteria. ${ }^{55}$ One of the main characteristics of SpA is the bone marrow edema of sacroiliac joints (SIJs) and spine, leading to chronic back pain. $\operatorname{axSpA}^{54}$ was the first report of the effect of CZP on inflammation of spine and SIJs in axSpA patients, including both AS and nr-axSpA patient populations, using magnetic resonance imaging (MRI). Moreover, improvements in Spondyloarthritis Research Consortium of Canada MRI, SIJ scores, and ankylosing spondylitis spine MRI score for activity, Berlin modifications, were observed in both CZP-dose arms compared to PBO overall and in both AS and nr-axSpA populations. Greater reductions in SIJ inflammation were observed for patient subgroups with $<5$ years' symptom duration, age $<45$ years, and in males. In this clinical trial, CZP was effective in reducing inflammation in the SIJs and spine, as assessed by MRI in patients with axSpA, and in both AS and nr-axSpa populations. ${ }^{54}$

\section{The application of CZP in $\mathrm{PsO}$}

Concerning PsO, CZP at an initial dose of $400 \mathrm{mg}$ followed by 200 or $400 \mathrm{mg}$ every 2 weeks was evaluated in a randomized, PBO-controlled, double-blind study. ${ }^{56}$ The drug results were significantly more effective than $\mathrm{PBO}$ in 
the treatment of patients with moderate to severe plaque psoriasis. Coprimary end points were $\geq 75 \%$ improvement from baseline in the Psoriasis Area and Severity Index (PASI 75) and a Physician's Global Assessment (PGA) of clear-almost clear at week 12. A 75\% decrease in PASI score was observed as early as the initial observation at week 2 in some CZP-treated patients. Therefore, CZP was well tolerated in patients with moderate to severe $\mathrm{PsO}$, with a low incidence of injection-site pain or treatment discontinuation due to AEs. ${ }^{51}$ A retreatment extension study was conducted in 71 CZP PASI 75 responders who relapsed during a 12to 24-week observation period without treatment. PASI 75 was achieved by $75 \%, 83 \%$, and $47 \%$ of patients in the CZP $200 \mathrm{mg}$, CZP $400 \mathrm{mg}$, and PBO groups, respectively $(P<0.001$ for both treatment arms vs PBO). A PGA score of clear-almost clear was achieved by $53 \%, 72 \%$, and $2 \%$, respectively ( $P<0.001$ for both treatment arms vs $\mathrm{PBO})$. In the retreatment study, median PASI scores were similar at week 12 in the first treatment and retreatment periods for both CZP groups. Serious AEs occurred in 3\%, 5\%, and $2 \%$ of CZP $200 \mathrm{mg}$, CZP $400 \mathrm{mg}$, and PBO patients, respectively. Treatment with CZP significantly improved psoriasis at week 12. Similar efficacy was observed at week 12 in patients receiving retreatment for loss of response after drug withdrawal. ${ }^{56}$

\section{Efficacy of CZP in PsA: rational use in psoriatic arthritis}

Clinical and experimental findings suggest that CZP has a unique property of distribution in inflamed tissues. Moreover, in a recent paper of Shu et al, CZP was effective in inhibiting human dermal microvascular endothelial cell expression of angiogenic adhesion molecules and decreased human dermal microvascular endothelial cell angiogenic chemokine secretion. ${ }^{57}$ At the same time, CZP downregulated TNF- $\alpha$-induced myeloid cell adhesion to endothelial cells and blocked leukocyte-endothelial cell adhesive interactions in RA synovial tissue, suggesting a novel role for CZP in blocking monocyte adhesion to inflamed synovial vasculature.$^{57}$ In this regard, PsA can be considered as a systemic disease that involves not only skin and joints but also such other organs as enthesis, vascular endothelium, and adipocyte tissue. PsA synovial tissue is typically characterized by the presence of high endothelial venules associated with immune cell infiltrates. ${ }^{16}$ Concerning only joint and enthesis involvement, Mease et al experienced for the first time the clinical efficacy and safety of CZP in PsA (RAPID-PsA).${ }^{47}$ Patients with active
PsA who had failed $\geq 1$ DMARD and could have failed $\leq 1$ anti-TNF- $\alpha$ were randomized PBO or CZP $400 \mathrm{mg}$ at week 0, 2 and 4 followed by either $200 \mathrm{mg}$ CZP or $400 \mathrm{mg}$ CZP. Patients receiving PBO who failed to achieve $\geq 10 \%$ decrease in tender-joint count and swollen-joint count at both weeks 14 and 16 were rescued and randomized at week 16 to receive CZP $200 \mathrm{mg}$ or CZP $400 \mathrm{mg}$. The clinical primary end point was ACR20 response at week 12. A total of 409 patients were randomized with similar baseline demographic characteristics, and 20\% of patients had previously failed an anti-TNF- $\alpha$ treatment. ACR20 response at week 12 was significantly higher in both CZP arms vs PBO. The majority of the overall response rate observed at week 24 was achieved by week 12. Response with CZP was rapid, with a greater ACR20 response as early as week 1 (7.4\% for PBO vs $21.0 \%$ for CZP $200 \mathrm{mg}[P=0.001]$ and vs $23.0 \%$ for CZP $400 \mathrm{mg}$ $[P<0.001])$. At weeks 12 and 24, both CZP arms showed significantly greater improvements than PBO in ACR50 and in ACR70. Greater improvements were also observed for both CZP arms in PASI 75, as well as in the Health Assessment Questionnaire Disability Index at week 24. AEs occurred at the rates of $68 \%$ vs $62 \%$ and serious AEs at $4 \%$ vs $7 \%$ in $\mathrm{PBO}$ vs CZP, respectively. The safety profile was similar to that observed with CZP in RA. ${ }^{47}$ The authors concluded that CZP effectively improved the signs and symptoms of arthritis, physical function, and skin manifestations of $\mathrm{PsO}$ in patients with PsA, with a safety profile similar to RA. ${ }^{53}$ Other clinical values, like enthesitis and nail psoriasis, were considered in the ongoing 158week RAPID-PsA trial (double-blind and PBO controlled to week 24 , dose-blind to week 48 , and then open-label to week 158). In patients with enthesitis (64.3\%), the Leeds Enthesis Index change from baseline at week 24 was -2.0 with CZP $200 \mathrm{mg}(P<0.001)$ and -1.8 with CZP $400 \mathrm{mg}$ $(P<0.003)$ vs -1.1 PBO. For patients with baseline nail disease (73.3\%), Nail Psoriasis Severity Index change from baseline at week 24 was -1.6 with CZP $200 \mathrm{mg}$ and -2.0 with CZP $400 \mathrm{mg}$ vs -1.1 PBO. No differences in Leeds Dactylitis Index change from baseline were observed in patients with baseline dactylitis. ${ }^{58}$

\section{Efficacy of CZP in radiographic progression in PsA}

Furthermore, the efficacy of CZP was also evaluated in radiographic progression in PsA patients. Gladman and colleagues performed a 24-week patient-reported outcome, phase III, double-blind, randomized, PBO-controlled study. 
Effect of CZP on the multiple facets of PsA included an analysis of changes from baseline of modified Total Sharp Score. CZP was efficacious in inhibiting radiographic progression compared to $\mathrm{PBO}$. Conventional radiographic imputation methods showed that CZP effectively inhibited radiographic progression in PsA patients. Significantly fewer patients had progression with either CZP dose compared to PBO. CZP was shown to be effective also in improvements in productivity at paid work and within the household, and increased participation in daily activities in patients with PsA. ${ }^{56}$ Compared to the other anti-TNF agents, CZP is characterized by a different mechanism of action, possibly due to both structure and signal transduction. These features could be related to exact epitopes to which the anti-TNF agents bound the anti-TNF.

\section{Conclusion}

Psoriatic arthritis should be rather considered as a systemic disease but the major clinical characteristics are involvement of joints, enthesis and skin. ${ }^{1}$ Pathogenetic and clinical evidence suggests the role of a complex interplay between chronic inflammatory processes and bone remodeling. ${ }^{14}$ Clinical guidelines and consensus statements on anti-TNF- $\alpha$ treatment are under constant revision, as data from longterm studies are becoming continuously available. CZP is effective and safe for the treatment of such inflammatory diseases as CD38, RA46, AS, SpA48 and PsO56 and has been evaluated for the treatment of PsA47, with various interesting results. Moreover, the properties of the drug have several advantages for a rapid remission of the diseases. Subcutaneous administration confers good compliance in treated patients for procedures and time of administration. Furthermore, considering PsA as a systemic disease, with major involvement of both skin and joints, clinical trials demonstrated that CZP is efficacious in $\mathrm{PsO}, \mathrm{PsA}$, and $\mathrm{SpA}$, as well as in radiographic progression. ${ }^{54,59}$ Moreover, CZP treatment should be taken into consideration not only in patients unresponsive to synthetic DMARDs but also in those patients who have failed to respond to previous antiTNF- $\alpha$ treatments, as has been demonstrated in several clinical trials. ${ }^{51,52}$

\section{Acknowledgments}

We would like to thank the rheumatology and dermatology unit health professionals of the University of Rome Tor Vergata. We gratefully acknowledge Dr Simone Emanuele Auteri, UCB Pharma, for scientific support in manuscript preparation.
Table I Clinical indications of certolizumab pegol

\begin{tabular}{lll}
\hline & Present indications & Futures indications \\
\hline Europe (EMA) & RA & CD, PsO, PsA and SpA \\
Swiss & RA, CD & PsO, PsA and SpA \\
Russia & RA, CD & PsO, PsA and SpA \\
USA & RA, CD & PsO, PsA and SpA \\
Canada & RA, CD & \\
Chile, Mexico & RA, CD & PsO, PsA and SpA \\
Argentina & RA, CD & \\
Australia & RA & CD, PsO, PsA and SpA \\
Asia & RA & CD, PsO, PsA and SpA \\
Japan & RA & \\
\hline
\end{tabular}

Notes: Cetolizumab pegol was approved for the treatment of rheumatoid arthritis in the EU, US and Canada in 2009, and for the treatment of Crohn's Disease in Switzerland in 2007 and in the USA in 2008. Certolizumab pegol is entering into an increasingly competitive marketplace, especially in rheumatoid arthritis, but clinical data demonstrate benefits across a range of other inflammatory disease.

Abbreviations: EMA, European Medicines Agency; RA, Rheumatoid Arthritis); CD, Crohn's disease; PsO, Psoriasis; PsA, Psoriatic Arthritis; SpA Spondyloarthritis.

\section{Disclosure}

The authors report no conflicts of interest in this work.

\section{References}

1. Christophers E. Psoriasis - epidemiology and clinical spectrum. Clin Exp Dermatol. 2001;26(4):314-320.

2. Kane D, Stafford L, Bresnihan B, FitzGerald O. A prospective, clinical and radiological study of early psoriatic arthritis: an early synovitis clinic experience. Rheumatology (Oxford). 2003;42(12): 1460-1468.

3. Partsch G, Steiner G, Leeb BF, Dunky A, Broll H, Smolen JS. Highly increased levels of tumor necrosis factor-alpha and other proinflammatory cytokines in psoriatic arthritis synovial fluid. J Rheumatol. 1997;24(3):518-523.

4. Gladman DD, Brockbank J. Psoriatic arthritis. Expert Opin Investig Drugs. 2000;9(7):1511-1522.

5. Laloux L, Voisin MC, Allain J, et al. Immunohistological study of entheses in spondyloarthropathies: comparison in rheumatoid arthritis and osteoarthritis. Ann Rheum Dis. 2001;60(4):316-321.

6. Saad AA, Ashcroft DM, Watson KD, Symmons DP, Noyce PR, Hyrich KL. Efficacy and safety of anti-TNF therapies in psoriatic arthritis: an observational study from the British Society for Rheumatology Biologics Register. Rheumatology (Oxford). 2010;49(4):697-705.

7. Punzi L, Podswiadek M, Sfriso P, Oliviero F, Fiocco U, Todesco S. Pathogenetic and clinical rationale for TNF-blocking therapy in psoriatic arthritis. Autoimmun Rev. 2007;6(8):524-528.

8. Strohal R, Chimenti S, Vena GA, Girolomoni G. Etanercept provides an effective, safe and flexible short- and long-term treatment regimen for moderate-to-severe psoriasis: a systematic review of current evidence. J Dermatolog Treat. Epub November 10, 2012.

9. van der Heijde D, Kavanaugh A, Gladman DD, et al. Infliximab inhibits progression of radiographic damage in patients with active psoriatic arthritis through one year of treatment: results from the induction and maintenance psoriatic arthritis clinical trial 2. Arthritis Rheum. 2007;56(8):2698-2707.

10. Papoutsaki M, Costanzo A, Chimenti MS, Chimenti S. Adalimumab for the treatment of severe psoriasis and psoriatic arthritis. Expert Opin Biol Ther. 2008;8(3):363-370.

11. Tracey D, Klareskog L, Sasso EH, Salfeld JG, Tak PP. Tumor necrosis factor antagonist mechanisms of action: a comprehensive review. Pharmacol Ther. 2008;117(2):244-279.

12. Ritchlin CT, Kavanaugh A, Gladman DD, etal. Treatment recommendations for psoriatic arthritis. Ann Rheum Dis. 2009;68(9): 1387-1394. 
13. FitzGerald O, McInnes I. Spondyloarthropathy: disease at the crossroads of immunity. Best Pract Res Clin Rheumatol. 2006;20(5):949-967.

14. Chimenti MS, Ballanti E, Perricone C, Cipriani P, Giacomelli R, Perricone R. Immunomodulation in psoriatic arthritis: focus on cellular and molecular pathways. Aut Rev 2013 Mar;12(5):599-606.

15. Hueber AJ, McInnes IB. Immune regulation in psoriasis and psoriatic arthritis-recent developments. Immunol Lett. 2007;114(2):59-65.

16. Codullo V, McInnes IB. Synovial tissue response to treatment in psoriatic arthritis. Open Rheumatol J. 2011;5:133-137.

17. Gerhard N, Krenn V, Magalhães R, Morawietz L, Brändlein S, König A. IgVH-genes analysis from psoriatic arthritis shows involvement of antigen-activated synovial B-lymphocytes. Z Rheumatol. 2002;61(6):718-727.

18. Cañete JD, Santiago B, Cantaert T, et al. Ectopic lymphoid neogenesis in psoriatic arthritis. Ann Rheum Dis. 2007;66(6):720-726.

19. Valesini G, Iannuccelli C, Marocchi E, Pascoli L, Scalzi V, Di Franco M. Biological and clinical effects of anti-TNFalpha treatment. Autoimmun Rev. 2007;7(1):35-41.

20. Baeten D, Kruithof E, Van den Bosch F, et al. Immunomodulatory effects of anti-tumor necrosis factor alpha therapy on synovium in spondylarthropathy: histologic findings in eight patients from an open-label pilot study. Arthritis Rheum. 2001;44(1):186-195.

21. Ohshima S, Mima T, Sasai M, et al. Tumour necrosis factor alpha (TNFa) interferes with Fas-mediated apoptotic cell death on rheumatoid arthritis (RA) synovial cells: a possible mechanism of rheumatoid synovial hyperplasia and a clinical benefit of anti-TNF therapy for RA. Cytokine. 2000;12(3):281-288.

22. Kruithof E, Baeten D, Van den Bosch F, Mielants H, Veys EM, De Keyser F. Histological evidence that infliximab treatment leads to downregulation of inflammation and tissue remodelling of the synovial membrane in spondyloarthropathy. Ann Rheum Dis. 2005;64(4): 529-536.

23. Chimenti MS, Perricone C, Graceffa D, et al. Complement system in psoriatic arthritis: a useful marker in response prediction and monitoring of anti-TNF treatment. Clin Exp Rheumatol. 2012;30(1):23-30.

24. Gossec L, Smolen JS, Gaujoux-Viala C, et al. European League Against Rheumatism recommendations for the management of psoriatic arthritis with pharmacological therapies. Ann Rheum Dis. 2012;71(1): 4-12.

25. Statkute L, Ruderman EM. Novel TNF antagonists for the treatment of rheumatoid arthritis. Expert Opin Investig Drugs. 2010;19(1): $105-115$.

26. Choy EH, Hazleman B, Smith M, et al. Efficacy of a novel PEGylated humanized anti-TNF fragment (CDP870) in patients with rheumatoid arthritis: a phase II double-blinded, randomized, dose-escalating trial. Rheumatology (Oxford). 2002;41(10):1133-1137.

27. Harris JM, Martin NE, Modi M. Pegylation: a novel process for modifying pharmacokinetics. Clin Pharmacokinet. 2001;40(7):539-551.

28. Nesbitt A, Fossati G, Bergin M, et al. Mechanism of action of certolizumab pegol (CDP870): in vitro comparison with other anti-tumor necrosis factor agents. Inflamm Bowel Dis. 2007;13(11):1323-1332.

29. Cominelli F. Cytokine-based therapies for Crohn's disease - new paradigms. $N$ Engl J Med. 2004;351(20):2045-2048.

30. Ueda N, Tsukamoto H, Mitoma H, et al. The cytotoxic effects of certolizumab pegol and golimumab mediated by transmembrane tumor necrosis factor $\alpha$. Ann Rheum Dis. 2012;71 Suppl 3:665.

31. Ohshima S, Saeki Y, Mima T, et al. Long-term follow-up of the changes in circulating cytokines, soluble cytokine receptors, and white blood cell subset counts in patients with rheumatoid arthritis (RA) after monoclonal anti-TNF alpha antibody therapy. $J$ Clin Immunol. 1999;19(5):305-313.

32. Taylor PC. Pharmacology of TNF blockade in rheumatoid arthritis and other chronic inflammatory diseases. Curr Opin Pharmacol. 2010;10(3): 308-315.

33. Kirchner S, Holler E, Haffner S, Andreesen R, Eissner G. Effect of different tumor necrosis factor (TNF) reactive agents on reverse signalling of membrane integrated TNF in monocytes. Cytokine. 2004;28(2):67-74
34. Watts AD, Hunt NH, Wanigasekara $\mathrm{Y}$, et al. A casein kinase I motif present in the cytoplasmic domain of members of the tumour necrosis factor ligand family is implicated in 'reverse signalling.' EMBO J. 1999;18(8):2119-2126.

35. Harashima S, Horiuchi T, Hatta N, et al. Outside-to-inside signal through the membrane TNF-alpha induces E-selectin (CD62E) expression on activated human CD4+ T cells. $J$ Immunol. 2001;166(1):130-136.

36. Mitoma $\mathrm{H}$, Horiuchi $\mathrm{T}$, Hatta $\mathrm{N}$, et al. Infliximab induces potent anti-inflammatory responses by outside-to- inside signals through transmembrane TNF-[alpha]. Gastroenterology. 2005;128(2): 376-392.

37. Eissner G, Kolch W, Scheurich P. Ligands working as receptors: reverse signaling by members of the TNF superfamily enhance the plasticity of the immune system. Cytokine Growth Factor Rev. 2004;15(5): 353-366.

38. van Lent PL, Blom AB, Grevers L, Sloetjes A, van den Berg WB. Toll-like receptor 4 induced FcgR expression potentiates early onset of joint inflammation and cartilage destruction during immune complex arthritis: Toll-like receptor 4 largely regulates FcgR expression by IL-10. Ann Rheum Dis. 2007;66(3):334-340.

39. Schreiber S, Rutgeerts P, Fedorak RN, et al. A randomized, placebocontrolled trial of certolizumab pegol (CDP870) for treatment of Crohn's disease. Gastroenterology. 2005;129(3):807-818. Erratum in: Gastroenterology. 2005;129(5):1808.

40. Sandborn WJ, Feagan BG, Stoinov S, et al. Certolizumab pegol administered subcutaneously is effective and well tolerated in patients with active Crohn's disease: results from a 26-week, placebo-controlled phase III study (PRECiSE 1). Gastroenterology. 2006;130 Suppl 2: A1-A912.

41. Kozuch PL, Hanauer SB. General principles and pharmacology of biologics in inflammatory bowel disease. Gastroenterol Clin North Am. 2006;35(4):757-773.

42. Colombel J, Sandborn WJ, Rutgeerts P, et al. Adalimumab induces and maintains clinical response and remission in patients with active Crohn's disease: results of the CHARM trial. Gastroenterology. 2006;130 Supp1 2:A1-A912.

43. Shen C, Assche GV, Colpaert S, et al. Adalimumab induces apoptosis of human monocytes: a comparative study with infliximab and etanercept. Aliment Pharmacol Ther. 2005;21(3):251-258.

44. Jazayeri JA, Carroll GJ. Fc-based cytokines: prospects for engineering superior therapeutics. Bio Drugs. 2008;22(1):11-26.

45. Palframan R, Airey M, Moore A, Vugler A, Nesbitt A. Use of biofluorescence imaging to compare the distribution of certolizumab pegol, adalimumab, and infliximab in the inflamed paws of mice with collagen-induced arthritis. J Immunol Methods. 2009;348(1-2):36-41.

46. Fleischmann R. The clinical efficacy and safety of certolizumab pegol in rheumatoid arthritis. Expert Opin Biol Ther. 2010;10(5):773-786.

47. Mease PJ, Fleischmann RM, Deodhar A et al. Effect of certolizumab pegol on signs and symptoms in patients with psoriatic arthritis: 24 week results of a phase 3 double blind randomized placebo-controlled study (RAPID-PsA). Ann Rheum Dis. 2012;71(Supp13):LB0001.

48. Sieper J, Kivitz AJ, Van Tubergen AM, et al. Rapid Improvements in Patient Reported Outcomes with Certolizumab Pegol in Patients with Axial Spondyloarthritis, Including Ankylosing Spondyltitis and NonRadiographic Axial Spondyloarthritis: 24 Week Results of a Phase 3 Double Blind Randomized Placebo-Controlled Study. Ann Rheum Disease. 2012;64(Supp110):558.

49. Deeks ED. Certolizumab Pegol: A Review of Its Use in the Management of Rheumatoid Arthritis. Drugs. 2013;22. [Epub ahead of print]

50. Furst DE, Keystone EC, Fleischmann R, et al. Updated consensus statement on biological agents for the treatment of rheumatic diseases, 2009. Ann Rheum Dis. 2010;69 Suppl 1:i2-29. Erratum in: Ann Rheum Dis. 2011;70(8):1519.

51. Furst DE, Shaikh SA, Greenwald M, et al. Evaluation of two dosing regimens of certolizumab pegol for maintenace of clinical response in patients with active rheumatoid arthritis: primary results from Doseflex, a Phase IIIB study. Ann Rheum Dis. 2012; 71(Suppl3):SAT0126. 
52. Fleischmann R, Vencovsky J, van Vollenhoven RF, et al. Efficacy and safety of certolizumab pegol monotherapy every 4 weeks in patients with rheumatoid arthritis failing previous disease-modifying antirheumatic therapy: the FAST4 WARD study. Ann Rheum Dis. 2009; 68(6):805-811.

53. Ramiro S, van Tubergen AM, Landewé RB. RAPID and FAST4 WARD trials: certolizumab pegol for rheumatoid arthritis. Expert Rev Clin Immunol. 2010;6(5):713-720.

54. Van der Heijde D, Maksymowych W, Landewé R, et al. Effect of certolizumab pegol on inflammation of spine and sacroiliac joints in patients with axial spondyloarthritis: 12 week magnetic resonance imaging results of a phase 3 double blind randomized placebocontrolled study. Arthritis Rheum. 2012; 64(Suppl10):1705

55. Sieper J, Rudwaleit M, Baraliakos X, et al. The Assessment of Spondyloarthritis International Society (ASAS) handbook: a guide to assess spondyloarthritis. Ann Rheum Dis. 2009;68 Suppl 2:ii1-ii44.
56. Reich k, Ortonne JP, Gottlieb AB, et al. Successful treatment of moderate to severe plaque psoriasis with the pegylated fab' certolizumab pegol: results of a phase II randomized, placebo-controlled trial with a re-treatment extension. Br J Dermatol. 2012;167(1):180-190.

57. Shu Q, Amin MA, Ruth JH, et al. Suppression of endothelial cell activity by inhibition of TNF $\alpha$. Arthritis Res Ther. 2012;14(2):R88.

58. Mease PJ, Fleischmann RM, Wollenhaupt J, et al. Effect of certolizumab pegol on signs and symptoms in patients with psoriatic arthritis with and without prior anti-TNF exposure: 24 week results of a phase 3 doubleblind randomized placebo-controlled study. Ann Rheum Dis. 2012;71 Suppl 3:150.

59. Gladman DD, Fleischmann RM, Coteur G, Woltering F, Mease P. Effect of certolizumab pegol on the multiple facets of psoriatic arthritis as reported by patients: 24 week patient reported outcome results of a phase 3 double blind randomized placebo-controlled study. Arthritis Rheum. 2012;64 Suppl 10:557.

\section{Publish your work in this journal}

Drug Design, Development and Therapy is an international, peerreviewed open-access journal that spans the spectrum of drug design and development through to clinical applications. Clinical outcomes, patient safety, and programs for the development and effective, safe, and sustained use of medicines are a feature of the journal, which has also been accepted for indexing on PubMed Central. The manuscript management system is completely online and includes a very quick and fair peer-review system, which is all easy to use. Visit http://www.dovepress.com/testimonials.php to read real quotes from published authors.

Submit your manuscript here: http://www.dovepress.com/drug-design-development-and-therapy-journal 